\title{
KERAGAMAN JENIS JAMUR YANG MENYERANG TANAMAN MAHONI (Swietenia Macrophylla KING.) DI KAMPUS UNIVERSITAS HASANUDDIN MAKASSAR, SULAWESI SELATAN
}

\author{
Diversity of Fungi Attaching Switenia macrophylla King at Hasanuddin University Campus, South Sulawesi. \\ Sulvia Darmuh¹, Astuti Arifi', Ira Taskirawati ${ }^{1}$ \\ ${ }^{1}$ Fakultas Kehutanan, Universitas Hasanuddin, Makassar. ${ }^{\circledR}$ corresponding author: tasqira@unhas.ac.id
}

\begin{abstract}
Many Mahogany (Switenia macrophylla King.) is used as the main tree in the area or the forestry industry plans. If the tree is planted monoculture, the mahogany stand has become highly vulnerable to pest and diseases, because monoculture tree plantations are an abundant food source for both organisms. This study aims to determine the types of fungi that attacking and cause disease in plant parts mahogany. The result showed that there are ten species of fungi that attack mahogany. Seven of them have been identified while the other cannot be identified. Fungi are attacked or negative associations in the roots, stem, leaves and fruits of plant mahogany. The seven species of fungi are Rhizopus arrhizus Fischer; Mucor racemosus Fres; Mycgone rosea Link; Absidia corymbifera (Cohn.) Sacc \& Trotter; Monilia sitophila (Mont.) Sacc; Cladosporium spharospermeum Penzig; and Myrothecium verrucaria (Orig.). Fungi that attack the roots of the tree are A. corymbifera (Cohn.) Sacc and C. spharospermeum Penzig. M. rosea Link and M. sitophila (Mont.) Sacc attacking the leaf. $R$. arrhizus Fischer and M. verrucaria (Orig.) attacks the stems of trees while Mucor racemosus Fres. Attacking the fruit of mahogany. Fungi that cannot be identified are a fungus that attacks the stems and leaves.
\end{abstract}

Key words : Switenia macrophylla King, Fungi

\section{A. PENDAHULUAN}

Tanaman mahoni merupakan salah satu tanaman komersil. Kayu tanaman mahoni dapat dijadikan vinir dekoratif dan kayu lapis. Selain itu, dapat pula dipakai untuk meubel, panil, perkapalan, balok percetakan dan barang kerajinan. Mahoni banyak dijadikan tanaman utama pada areal atau hutan tanaman industri. Jika tanaman mahoni ditanam secara monokultur, maka tegakan mahoni ini menjadi sangat rentan terhadap serangan hama dan penyakit, karena hutan tanaman monokultur merupakan sumber makanan yang berlimpah bagi kedua organisme tersebut.

Sehubungan dengan hal tersebut di atas, maka perlu dilakukan penelitian untuk mengidentifikasi jamur perusak kayu terutama pada kayu tanaman mahoni (Swietenia macrophylla King.) yang terdapat di sekitar Kampus Unhas Tamalanrea Kecamatan Tamalanrea, Makassar untuk dijadikan sebagai bahan informasi tentang keanekaragaman jenis jamur yang merusak pada kayu tersebut.

Penelitian ini bertujuan untuk mengetahui jenis-jenis jamur yang menyerang dan menyebabkan penyakit pada bagian-bagian pohon mahoni. Hasil penelitian ini diharapkan bermanfaat dan dapat memberikan informasi mengenai keanekaragaman jenis jamur yang menyerang dan menyebabkan penyakit pada pohon mahoni dan

Diterima: 24 Januari 2018: Disetuiui: 2 Maret 2018 selanjutnya informasi tersebut dapat digunakan dalam menentukan teknik pengendaliannya.

\section{B. BAHAN DAN METODE}

Alat-alat yang digunakan dalam penelitian ini adalah gelas ukur $1000 \mathrm{ml}$ dan $200 \mathrm{ml}$, cawan petri, erlenmeyer $1000 \mathrm{ml}$, tabung reaksi, pipet mikro/batang, pinset, pisau preparat, cutter, spatula, timbangan, kompor, inkubator, autoclave, handcase, object glass dan deck glass, mikroskop binocular, lampu UV, lemari pendingin, oven, bunsen, kawat ose, gunting, pisau, wadah, panci, kamera digital.

Bahan-bahan yang diperlukan dalam penelitian ini adalah sampel jamur yang diperoleh dari pohon mahoni yang terserang jamur, kentang 200 gram, dekstrosa atau gula putih 10 gram, agar batang atau tepung 15 gram, aquadest $1000 \mathrm{ml}$, chloramphenicol sebagai anti bakteri, alkohol $70 \%$ untuk sterilisasi, spritus, aluminium foil, plastic wrap, plastik obat, kapas, selotip, kertas saring, kain saring, kertas label dan alat tulis menulis.

Prosedur penelitian dilakukan dengan cara mengambil pohon yang diduga terkena serangan jamur. Sampel yang diambil berasal dari bagian akar, batang, daun, dan buah. Sampel diambil menggunakan pisau dan dimasukkan ke dalam plastik klip. Jamur yang diperoleh di lapangan di isolasi pada medium tumbuh dan dibiakkan sampai diperoleh isolate murni jamur yang 
Table 1. The observation of microscopic fungi on S. macrophylla King.

\begin{tabular}{|c|c|c|c|c|c|c|}
\hline \multirow[b]{2}{*}{ No. } & \multirow[b]{2}{*}{ Jenis Jamur } & \multicolumn{4}{|c|}{ Asal Ditemukan } & \multirow[b]{2}{*}{ Kelas } \\
\hline & & Akar & Batang & Daun & Buah & \\
\hline 1. & Rhizopus arrhizus & & $\checkmark$ & & & Zygomycetes \\
\hline 2. & Mucor racemosus & & & & $\checkmark$ & Zygomycetes \\
\hline 3. & Mycogone rosea & & & $\checkmark$ & & Ascomycetes \\
\hline 4. & Absidia corymbifera & $\checkmark$ & & & & Zygomycetes \\
\hline 5. & Monilia sitophilla & & & $\checkmark$ & & Deuteromycetes \\
\hline 6. & Cladosporium sphaerospermum & $\checkmark$ & & & & Deuteromycetes \\
\hline 7. & Myrothecium verrucaria & & $\checkmark$ & & & Deuteromycetes \\
\hline
\end{tabular}

diinginkan. Selama pembiakan berlangsung, biakan jamur ini disimpan pada inkubator pada suhu sekitar $30^{\circ} \mathrm{C}$. Identifikasi dilakukan dengan mengamati ciri makroskopis dan mikroskopis jamur. Ciri makroskopis yang diamati adalah warna jamur, koloni jamur, dan bentuk tubuh buah jamur. Pengamatan ciri mikroskopis mencakup hifa, spora, sporangium, konidia, konidofor, dan ciri khusus yang akan menentukan jenis jamur tersebut. Identifikasi dilakukan dengan mengacu pada buku identifikasi jamur: Barnett and Hunter (1980), Streets (1980), Fassatiova (1986), Tambunan dan Nandika (1982), dan Rahayu (1998).

\section{HASIL DAN PEMBAHASAN}

Hasil Hasil pengamatan secara makroskopis dan mikroskopis pada sampel jamur yang menyerang tanaman mahoni di Kampus Unhas Tamalanrea Makassar, diidentifikasi beberapa jenis jamur, seperti pada Tabel 1.

Penjelasan lebih rinci mengenai jenis-jenis jamur yang menyerang tanaman mahoni beserta gejala dan tanda yang ditimbulkan sebagai berikut:

\section{Rhizopus arrhizus Fischer}

Jamur jenis $R$. arrhizus Fischer diperoleh dari kulit batang tanaman mahoni. Tanda-tanda kerusakan yang

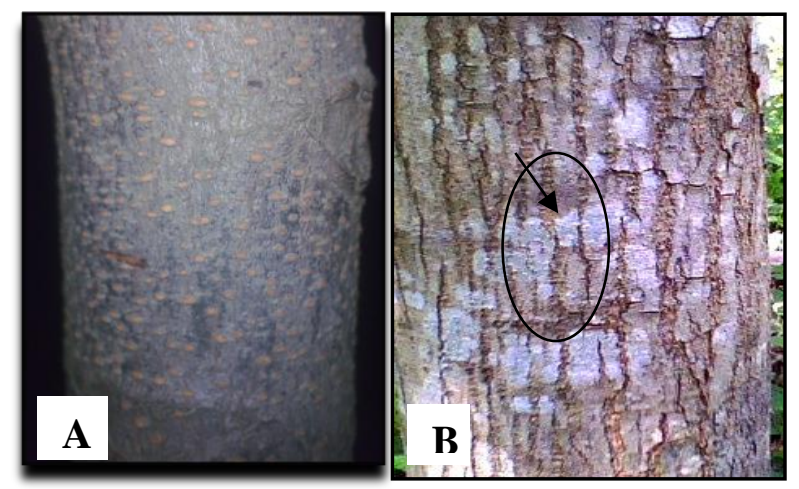

Gambar 1. (A) Bagian batang yang tidak terserang jamur; (B) Gejala dan tanda serangan jamur $R$. arrhizus pada kulit batang mahoni ditimbulkan pada tanaman mahoni adalah terdapatnya benang-banang putih yang lama-kelamaan menjadi hijau serta bercak-bercak pada batang yang semakin hari akan semakin membesar dan menebal. Gejala dan tanda terserangnya kulit batang tanaman mahoni dapat dilihat pada Gambar 1B.

Menurut Praweda (2008), jamur ini dapat diklasifikasikan sebagai berikut:

$\begin{array}{ll}\text { Kingdom } & \text { : Fungi } \\ \text { Phyllum } & : \text { Zygomycota } \\ \text { Class } & : \text { Zygomycetes } \\ \text { Ordo } & : \text { Mucorales } \\ \text { Family } & : \text { Mucoraceae } \\ \text { Genus } & : \text { Rhizopus } \\ \text { Spesies } & : \text { Rhizopus arrhizus Fischer }\end{array}$

Secara makroskopis perkembangan miselia pada biakan kultur mencapai $7 \mathrm{~cm}$ dalam lima hari pembiakan. Pada awal pertumbuhan, koloni berwarna putih dengan tekstur halus. Setelah dua hari pembiakan, warna koloni berubah menjadi hijau kecoklatan (Gambar 2A). Menurut Gandjar (2000), jamur ini dapat juga ditemukan pada kayu yang lapuk dan dapat diisolasi dari tanah serta bersifat patogen pada tumbuhan hidup.

Pada pengamatan mikroskopis hifa yang tumbuh memiliki dinding yang tebal, sporangiofor tumbuh di sepanjang hifa. Kolumellanya berbentuk oval atau elips,

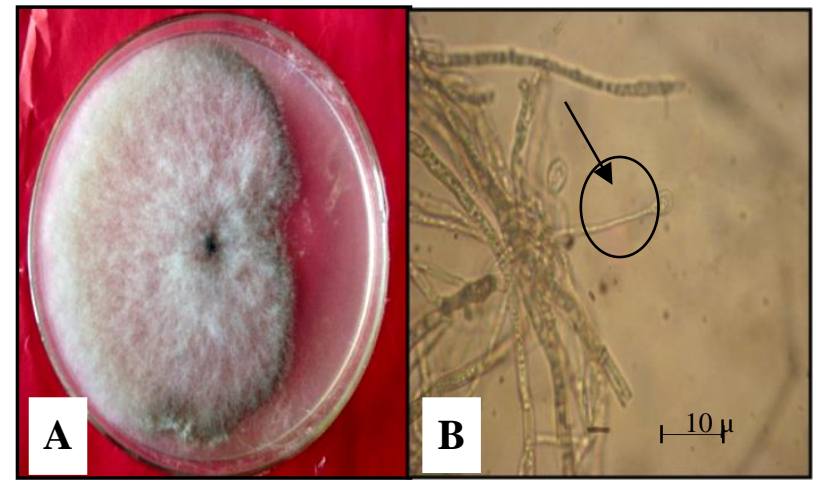

Gambar 2. R. arrhizus Fischer. (A) Pertumbuhan jamur pada hari ke-5 dikulturkan; (B) Penampakan mikroskopis kolumella pada perbesaran 40 kali. 
dengan ukuran 10-20 $\mu \mathrm{m}$ dengan dinding yang tebal (Gambar 2B). Terdapat banyak rhizoid (bentuk seperti akar yang merupakan hifa yang menembus subtrat dan berfungsi untuk menyerap makanan) dan sporangiofor yang berkelompok. Sebagian sporangiofornya yang pendek akan tumbuh membesar. Sporangiofornya (tangkai sporangium) muncul dari stolon (hifa yang membentuk jaringan di permukaan subtrat) bersama rhizoidnya. Menurut Gandjar (2000), ketika rhizoidnya tidak berproduksi maka sporangiofornya akan menebal.

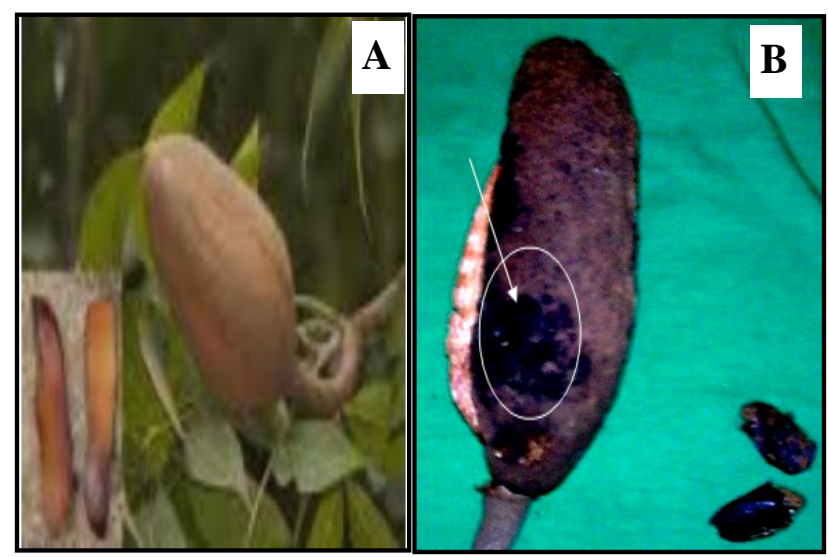

Gambar 3. (A) Buah yang tidak terserang jamur; (B) Buah yang terserang jamur $M$. racemosus Fres

\section{Mucor racemosus Fres.}

Jamur jenis $M$. racemosus diperoleh dari hasil isolasi bagian buah tanaman mahoni. Tanda-tanda serangan yang ditimbulkan adalah timbulnya bintik-bintik hitam seperti tepung pada buah mahoni akibatnya buah yang terserang lama kelamaan akan menjadi busuk (Gambar 3B). Menurut Streets (1980), jamur ini menyebabkan buah ubi jalar yang disimpan menjadi busuk dan berwarna coklat.

Menurut Streets (1980), jamur ini dapat diklasifikasikan sebagai berikut:

$\begin{array}{ll}\text { Kingdom } & \text { : Fungi } \\ \text { Phyllum } & : \text { Zygomycota } \\ \text { Class } & : \text { Zygomycetes } \\ \text { Ordo } & : \text { Mucorales } \\ \text { Family } & : \text { Mucoraceae } \\ \text { Genus } & : \text { Mucor } \\ \text { Spesies } & : \text { Mucor recemosus Fres. }\end{array}$

Secara makroskopis, pertumbuhan miselium jamur M. racemosus Fres pada biakan kultur mencapai diameter $8 \mathrm{~cm}$. Pada awal pembentukannya, miselia berwarna putih, pada hari keempat setelah pertumbuhan, warna miselia menjadi putih keabu-abuan dan bertekstur halus seperti kapas. Hifa jamur tumbuh menutupi medium biakan (Gambar 4A). Menurut Gandjar (2000), jamur ini kosmopolit dalam tanah.
Pada pengamatan mikroskopis jamur M. racemosus Fres sporangiofornya bercabang dan memiliki kolumela yang berbentuk elips atau oval (Gambar 4B). Jamur jenis ini juga memiliki sporangiofor bercabang, cabang yang pendek kadang-kadang membengkok, biasanya

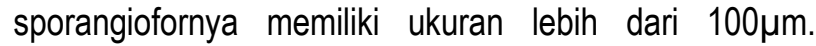
Sporangia semula berwarna hialin kemudian kecoklatan hingga abu-abu, berdiameter sampai $80 \mu \mathrm{m}$, dan dinding berduri. Kolumella berbentuk obvoid, elips, atau silindriselips, sedikit piriform, umumnya dengan basis yang rata dengan diameter $3,7 \quad-\quad 5,5 \mu \mathrm{m}$. Sporangiospora berbentuk elips yang lebar hingga semi bulat.

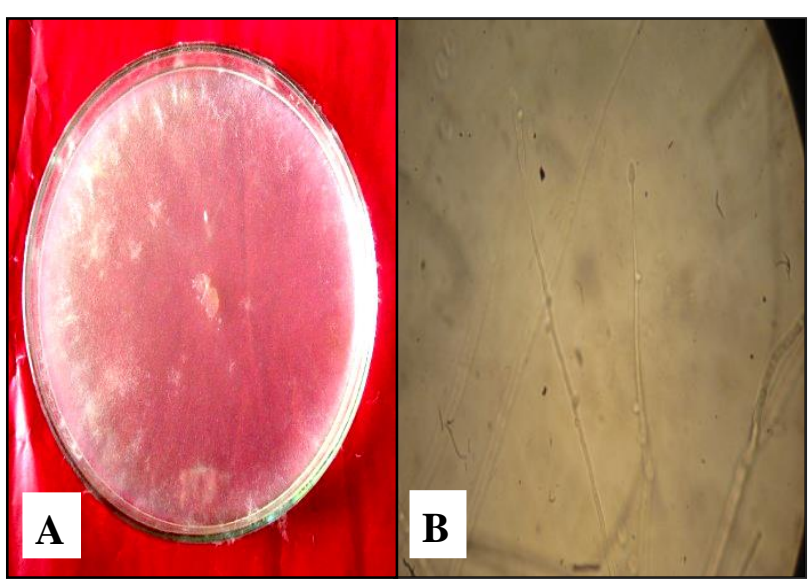

Gambar 4. M. recemosus Fres. (A) Pertumbuhan jamur pada hari ke-5 dikulturkan; (B) Penampakan mikroskopis kolumella pada perbesaran 40 kali.

\section{Mycogone rosea Link.}

Jamur jenis $M$. rosea diperoleh dari hasil isolasi bagian ujung daun tanaman mahoni. Tanda yang ditimbulkan adalah sebagian warna daun berubah kecoklatan. Gejala yang terjadi adalah mengeringnya sebagian daun yang terserang jamur (Gambar 5B).

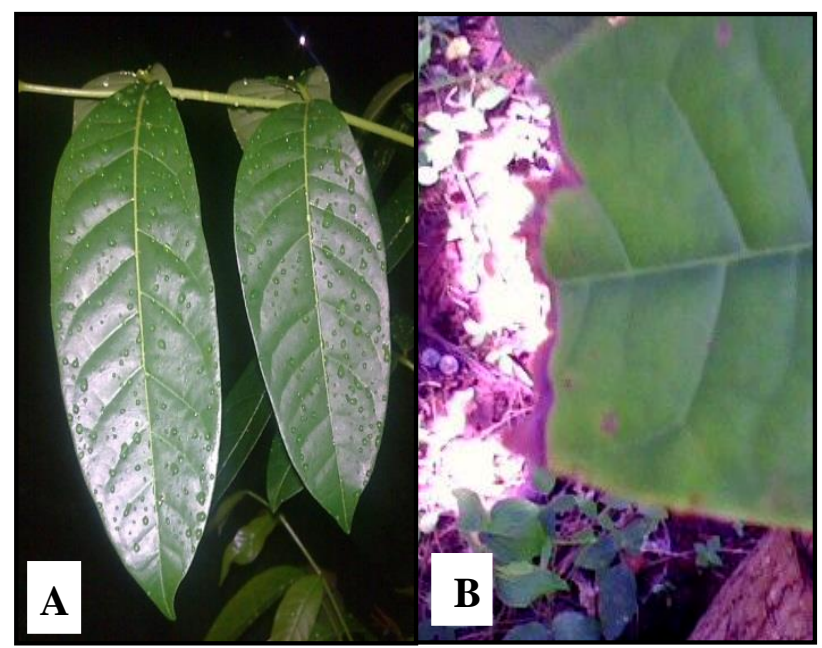

Gambar 5. (A) Daun yang masih sehat; (B) Daun yang terserang jamur M. Rosea 
Menurut Alexopoulus dan Mims (1979), jamur ini dapat diklasifikasikan sebagai berikut:
Kingdom
: Fungi
Phyllum
Class
Order
Family
Genus
Spesies
: Ascomycota
: Ascomycetes
: Hypocreales
: Hypocreaceae
: Mycogone
: Mycogone rosea Link.

Berdasarkan pengamatan makroskopis, dalam waktu 5 hari setelah pembiakan, koloni telah menutupi seluruh permukaan medium biakan, berwarna putih dan bertekstur halus (Gambar 6A). Jamur ini dibiakkan dan disimpan di inkubator dengan suhu sekitar $30^{\circ} \mathrm{C}$.

Pada pengamatan mikroskopis, konidia yang dihasilkan tersebar uniseluler, berbentuk bulat lonjong. Tetapi hanya memiliki 2-3 sekat dengan ukuran yang hampir sama dan memiliki dinding yang agak tebal. Kisaran ukuran dari konidia jamur M. rosea adalah sekitar 7 - $13 \mu \mathrm{m}$ (Gambar 6B). Apikal sel aleuriospore berdinding tebal dengan diameter $25-43 \mu \mathrm{m}$. Menurut Fassatiova (1986), dalam memproduksi aleuriospore, konidia dan konidiofor M. rosea berbentuk seperti konidia dan konidiofor pada Verticillium. Di alam jamur ini hidup sebagai parasit.

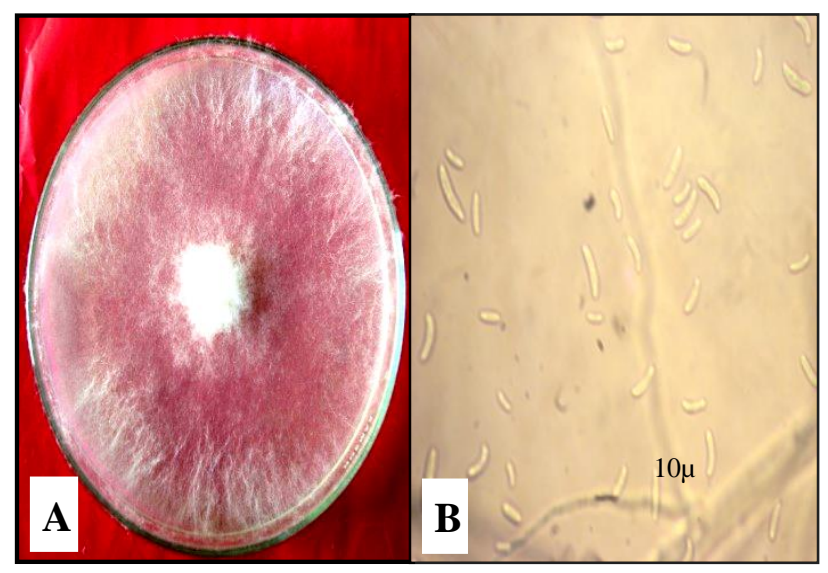

Gambar 6. M. rosea Link. (A) Pertumbuhan jamur pada hari ke-5 dikulturkan; (B) Penampakan mikroskopis konidia pada perbesaran 40 kali.

\section{Absidia corymbifera (Cohn) Sacc. \& Trotter}

Jamur jenis $A$. corymbifera diperoleh dari hasil isolasi bagian akar tanaman mahoni. Tanda-tanda penyerangan jamur ini adalah akar berwarna coklat kehitaman, sedangkan gejala yang ditimbulkan adalah pembengkakan pada akar. Gejala lain yang ditimbulkan yaitu keluarnya getah dari bagian akar yang terkena serangan jamur A. corymbifera (Gambar 7B).

Menurut Streets (1980), jamur ini dapat diklasifikasikan sebagai berikut:

$\begin{array}{ll}\text { Kingdom } & : \text { Fungi } \\ \text { Phyllum } & : \text { Zygomycota } \\ \text { Class } & : \text { Zygomycetes }\end{array}$
Ordo
Family
Genus
Spesies
: Mucorales
: Mucoraceae
: Absidia
: Absidia corymbifera

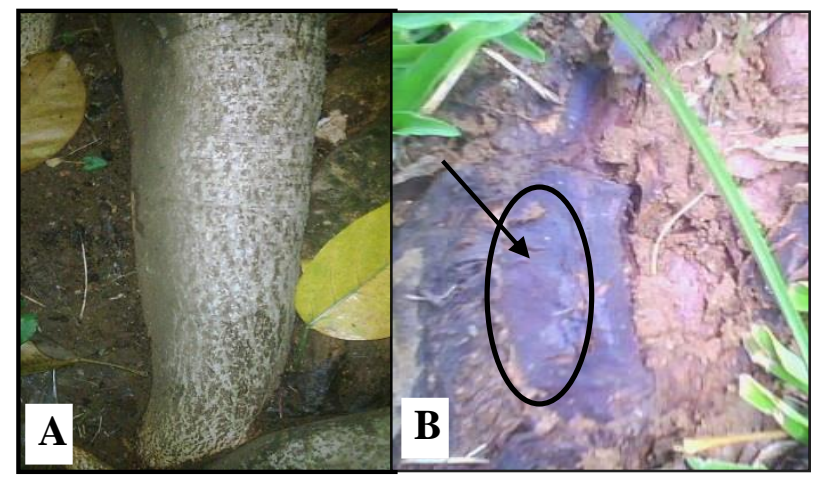

Gambar 7. (A) Akar yang masih sehat; (B) Akar yang terserang jamur A. corymbifera.

Berdasarkan pengamatan makroskopis pada medium biakan, miselia tumbuh menutupi permukaan medium biakan kurang dari tujuh hari, bertekstur halus, berwarna putih atau abu-abu muda. Pada hifa tersebut juga terlihat serbuk pada beberapa spot yang berwarna puth mengkilat. Hifa berwarna hialin hingga kecoklatan (Gambar 8A). Menurut Gandjar (2000), spesies ini bersifat heterotalik. Spesies ini tersebar luas di tanah, dan jamur ini juga spatogen untuk manusia.

Pada pengamatan mikroskopis, ujung konidiofornya bercabang dua atau tiga. Hifanya panjang, tidak bersekat dan memiliki dinding yang halus (Gambar 8B). Konidiofor berukuran lebih dari $70 \mu \mathrm{m}$ berdinding halus atau sedikit kasar, tampak sederhana atau kadang-kadang bercabang-cabang, muncul secara soliter dari stolon, dan membentuk kelompok terdiri atas tiga hingga tujuh dalam suatu untiran. Menurut Gandjar (2000), sporangia kurang lebih berbentuk piriform. Sporangiospora bervariasi bentuknya dari semi bulat hingga lonjong-elips, berwarna hialin hingga abu-abu muda dan berdinding halus.

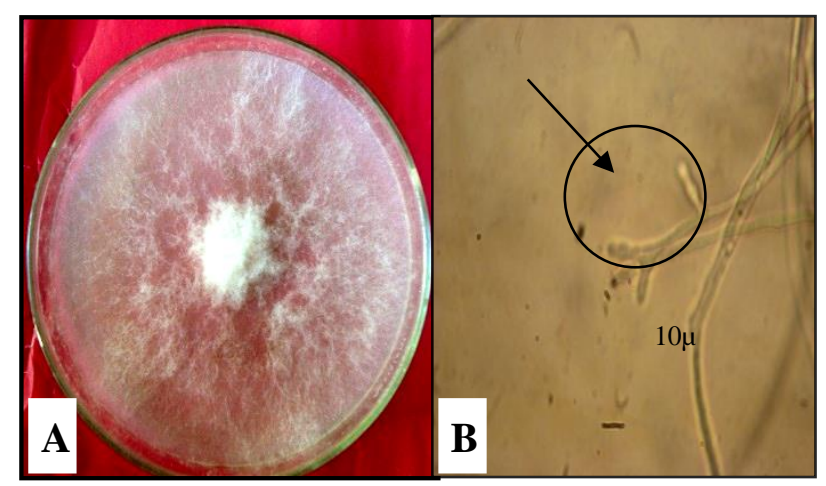

Gambar 8. A. corymbifera (A) Pertumbuhan jamur pada hari ke-5 dikulturkan; (B) Penampakan mikroskopis konidiofor pada perbesaran 40 kali. 


\section{Monilia sitophila (Mont.) Sacc.}

Jamur jenis M. sitophila diperoleh dari hasil isolasi daun tanaman mahoni. Tanda-tanda daun yang terserang jamur M. sitophila adalah warna daun berubah menjadi kecoklatan dan timbul bercak-bercak coklat pada helaian daun. Gejala yang terjadi adalah ketidaknormalan bentuk dan pertumbuhan bagian tepi daun seperti mengeriting dan mengerut (Gambar 9B).

Menurut Roger (2001), jamur jenis ini diklasifikasikan sebagai berikut:

$\begin{array}{ll}\text { Kingdom } & \text { : Fungi } \\ \text { Phyllum } & \text { : Amastigomycota } \\ \text { Sub divisi } & \text { : Deuteromycotina } \\ \text { Class } & \text { : Deuteromycetes } \\ \text { Ordo } & \text { : Moniliales } \\ \text { Family } & \text { : Moniliaceae } \\ \text { Genus } & \text { : Monilia } \\ \text { Spesies } & \text { :Monilia sitophila (Mont.) Sacc. }\end{array}$

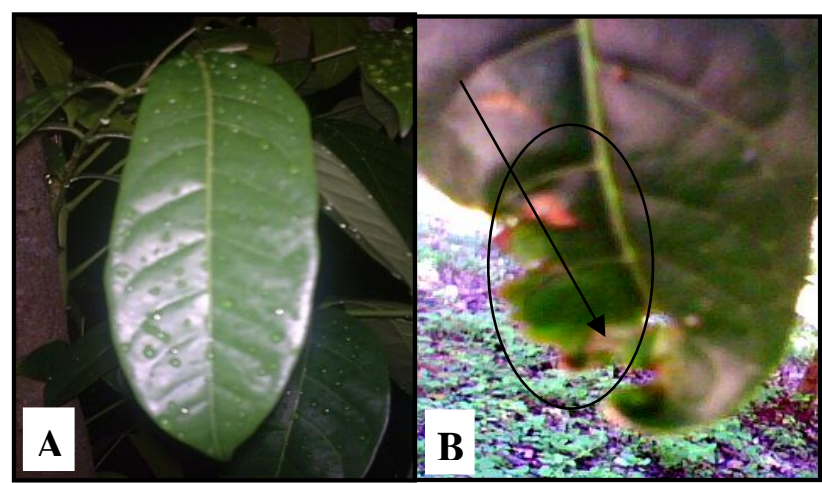

Gambar 9. (A) Daun yang masih sehat; (B) Daun yang terserang oleh jamur M. sitophila

Berdasarkan pengamatan makroskopis yang dilakukan, koloni hifa tumbuh menyebar, berwarna putih dan memiliki tekstur yang halus. Dalam waktu lima hari hifa dapat tumbuh menutupi medium biakan yang dinkubasi pada suhu $30^{\circ} \mathrm{C}$ (Gambar 10A). Menurut Dharmaputra (1997), sebagian besar jamur jenis ini hidup sebagai saproba, tetapi ada juga yang menjadi parasit tumbuhan, predator, hewan atau patogen manusia, hampir 20 spesies dari jenis ini merupakan pengurai dan ada pula yang dimanfaatkan sebagai cendawan industri.

Pada pengamatan mikroskopis, konidiofor bercabang dan memiliki rantai yang panjang. Miselium jamur ini menyebar pada subtrat, berwarna terang. Konidium termuda berada pada ujung rantai. Umumnya konidia berbentuk elips atau oval, berwarna hialin atau terang, dan saling bersambung (Gambar $10 \mathrm{~B}$ ). Konidia berjumlah banyak dan bagian miselia bercabang dan memiliki dinding. Menurut Fassatiova (1986), konidia semula akan berwarna putih kemudian menjadi orange pada saat pembentukan spora.

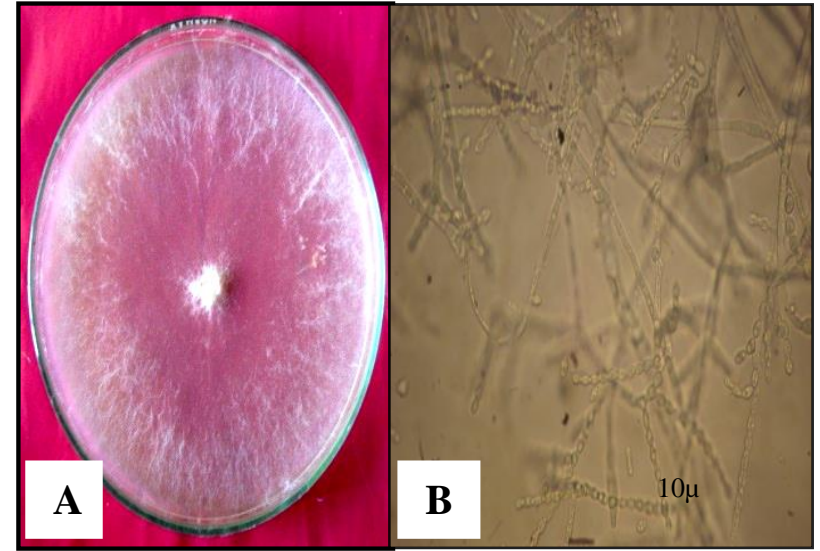

Gambar 10. M. sitophila. (A) Pertumbuhan jamur pada hari ke-5 dikulturkan; (B) Penampakan konidiofor pada perbesaran 40 kali.

\section{Cladosporium sphaerospermum Penzig}

Jamur jenis $\mathrm{C}$. sphaerospermum diperoleh dari hasil isolasi akar tanaman mahoni. Tanda-tanda yang ditimbulkan adalah akar berwarna coklat kehitaman sedangkan gejala yang ditimbulkan adalah kanker pada akar, merusak lapisan epidermis akar dan menyebabkan terkelupasnya akar (Gambar 11B).
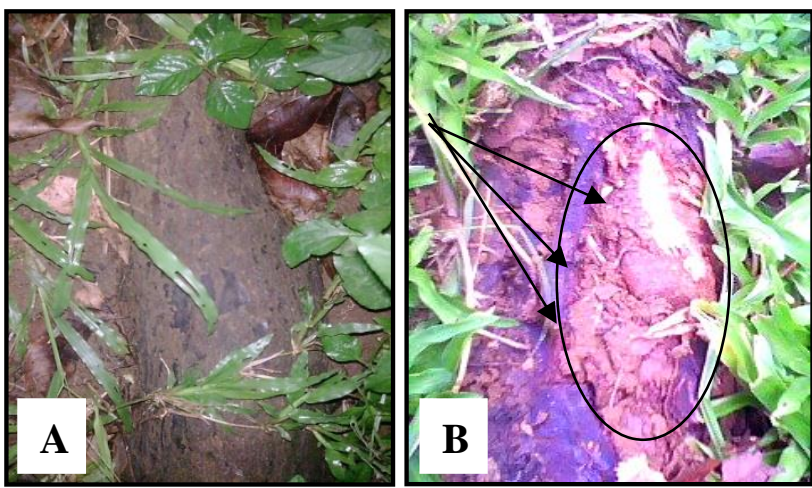

Gambar 11. (A) Akar mahoni yang masih sehat; (B) Akar yang terserang jamur

Menurut Kuo (2003), jamur C. sphaerospermum dapat diklasifikasikan sebagai berikut:

$\begin{array}{ll}\text { Kingdom } & \text { : Fungi } \\ \text { Pyllum } & \text { : Amastigomycota } \\ \text { Class } & \text { : Deuteromycetes } \\ \text { Ordo } & \text { : Moniliales } \\ \text { Family } & : \text { Dematiaceae } \\ \text { Genus } & : \text { Cladosporium } \\ \text { Spesies } & : \text { Cladosporium } \\ & \text { sphaerospermum }\end{array}$

Berdasarkan pengamatan makroskopis yang dilakukan pada medium biakan, hifa jamur $C$. sphaerospermum berwarna putih kehijauan. Miselium tumbuh menutupi medium biakan setelah lima hari 
diinkubasi pada suhu sekitar $30^{\circ} \mathrm{C}$ (Gambar 12A). Menurut Gandjar (2000), jamur ini memiliki sebaran yang luas di seluruh dunia dan berperan sebagai penyerang sekunder pada aneka macam tanaman. Dapat diisolasi dari tanah, udara, manusia maupun hewan.

Pada pengamatan mikroskopis, konidiofor dan konidia tersebar di sekitar hifa. Konidia dan ramokonidia memiliki dinding tebal dengan bentuk yang bervariasi, mulai dari oval atau elips dan juga memanjang, (Gambar 24B). Konidia berukuran panjang $3-10 \mu \mathrm{m}$ serta lebar 3 - $5 \mu \mathrm{m}$ dan tidak bersekat sedangkan ramokonidia berukuran lebih panjang, yaitu sekitar $8-12 \mu \mathrm{m}$ dengan lebar yang sama. Selain tersebar soliter, sebagian konidia juga bergabung dengan ramokonidia.
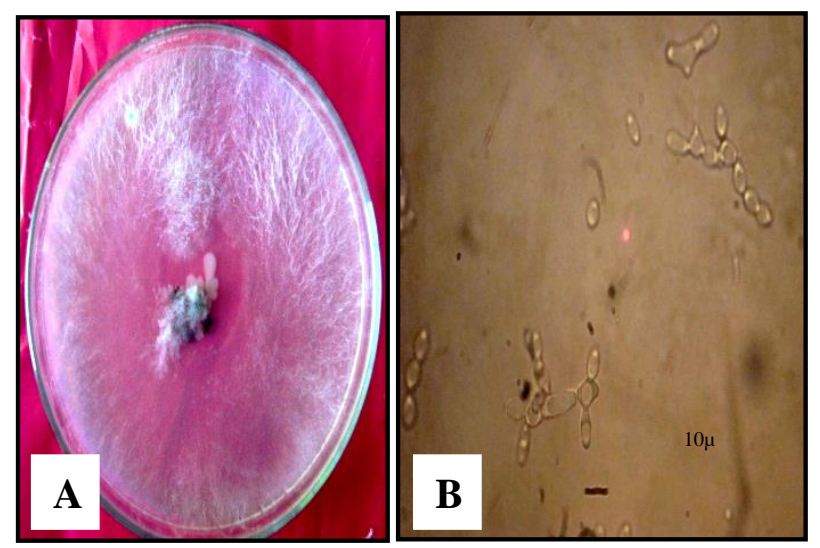

Gambar 12. C. sphaerospermum. (A) Pertumbuhan jamur padahari ke-5 dikulturkan; (B) Penampakan mikroskopis konidia pada perbesaran 40 kali.

\section{Myrothecium verrucaria (Orig.)}

Jamur M. verrucaria berasal dari hasil isolasi bagian kulit batang tanaman mahoni. Tanda-tanda yang ditimbulkan jamur $M$. verrucaria adalah batang yang terserang menjadi coklat kehitaman sehingga menimbulkan gejala kanker batang yang merusak lapisan epidermis batang tanaman mahoni (Gambar 13 B).

Berdasarkan pengamatan makroskopis pada media biakan, koloni awal yang tumbuh berwarna putih terang dengan tekstur yang halus seperti kapas. Koloni hifa tumbuh berkumpul di beberapa bagian pada cawan petri terutama pada bagian tengah medium namun tetap tumbuh halus di seluruh permukaan medium. Hifa tumbuh menutupi medium biakan setelah lima hari diinkubasi pada suhu sekitar $30^{\circ} \mathrm{C}$ (Gambar $14 \mathrm{~A}$ )

- Menurut Kirk (2008), jamur ini dapat diklasifikasikan sebagai berikut:

$\begin{array}{ll}\text { Kingdom } & : \text { Fungi } \\ \text { Phyllum } & : \text { Amastigomycota } \\ \text { Sub divisi } & : \text { Deuteromycotina } \\ \text { Class } & : \text { Deuteromycetes } \\ \text { Ordo } & : \text { Tuberculariales } \\ \text { Family } & : \text { Tuberculariaceae } \\ \text { Genus } & : \text { Myrothecium }\end{array}$

Spesies

\section{: Myrothecium verrucaria} (Orig.)

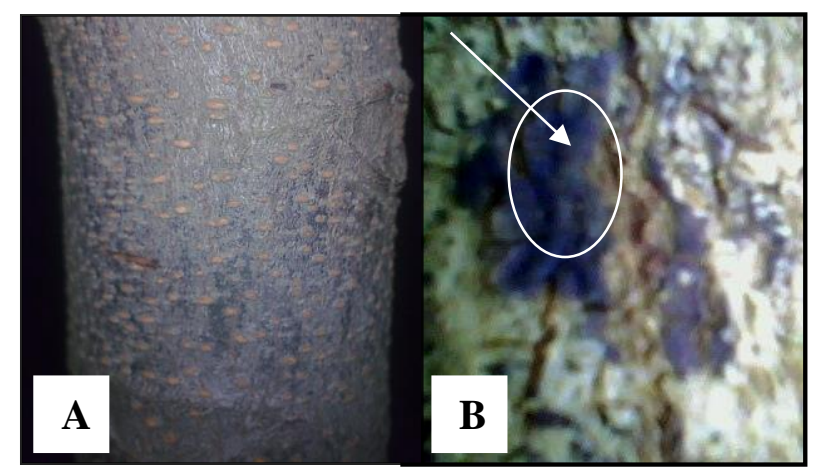

Gambar 13. (A) Batang mahoni yang masih sehat; (B) Batang mahoni yang terserang jamur M. verrucaria.

Pada pengamatan mikroskopis yang dilakukan, konidiofor bercabang dengan dinding yang tipis. Konidia tersebar di sekitar konidiofor, memiliki dua sekat dengan ukuran yang relatif sama yaitu panjang sekitar $3-7 \mu \mathrm{m}$ dengan lebar $2-3 \mu \mathrm{m}$. Konidia berbentuk elips (Gambar $14 \mathrm{~B})$. Konidia berwarna hialin atau terang. Menurut Fassatiova (1986), apabila konidia yang terlepas mulai bergabung maka sporodokhianya akan berwarna hitam dan membesar pada ujungnya dengan ukuran mencapai 6-10 $\mu \mathrm{m}$, bertekstur halus dengan dua atau tiga bagian cadangan minyak.

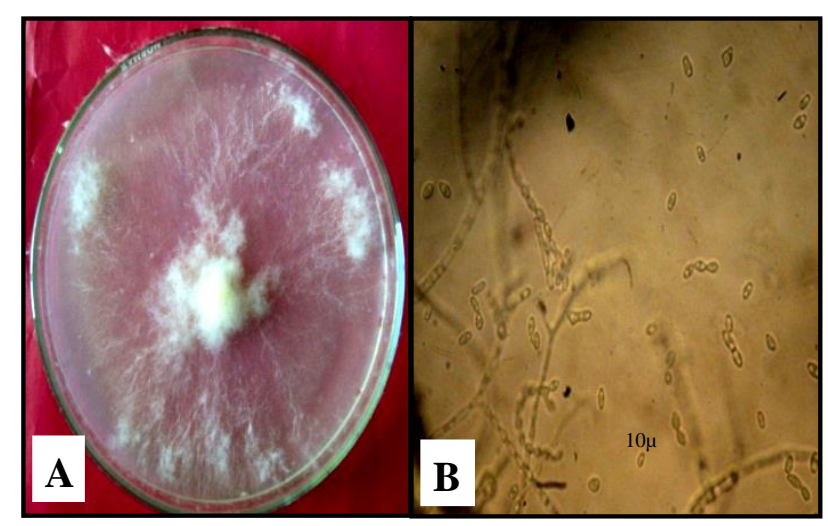

Gambar 14. M. verrucaria. (A) Pertumbuhan jamur pada hari ke-5 dikulturkan; (B) Penampakan mikroskopis konidia pada perbesaran 40 kali.

Selain mendapatkan tujuh jenis jamur yang dapat teridentifikasi, diperoleh pula tiga jenis jamur yang belum teridentifikasi. Jamur tersebut merupakan hasil isolasi dari bagian batang, dan daun. Gejala dan penampakan mikroskopis dapat dilihat secara rinci seperti berikut:

\section{Jamur pada batang yang belum teridentifikasi}

Gejala dan tanda yang ditimbulkan adalah kulit batang tanaman mahoni berwarna coklat kehitaman. Pada pengamatan mikroskopis yang dilakukan, konidia dan ramokonidia menyebar secara soliter. Ukuran konidia 
berkisar antara $8-15 \mu \mathrm{m}$. sedangkan ramokonidia berukuran lebih panjang, sekitar $15-20 \mu \mathrm{m}$. Konidia dan ramokonidia memiliki dinding yang tipis dan di dalamnya terlihat berisi zat cair. Jamur ini termasuk dalam kelas Deuteromycetes tapi belum dapat teridentifikasi sampai pada nama spesies.

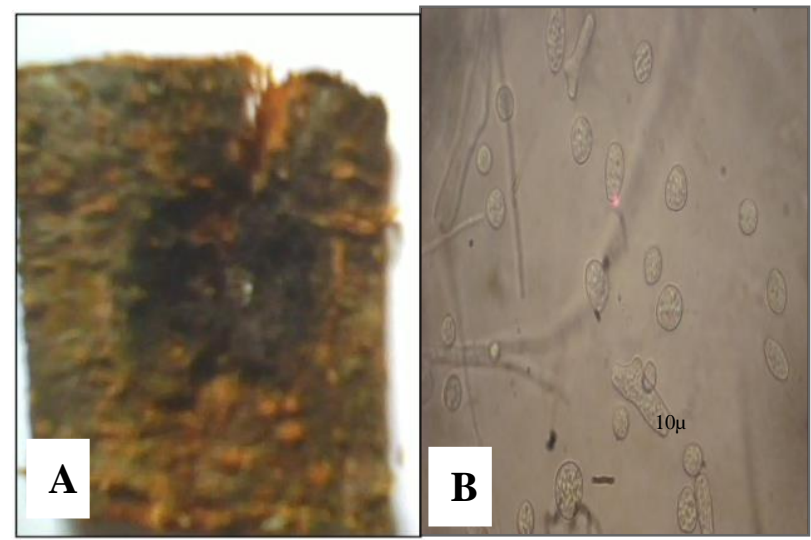

Gambar 15. (A) Gejala yang ditemukan pada batang; (B) Penampakan mikroskopis miselia dan konidia jamur yang ditemukan pada batang

\section{Jamur pada daun yang belum teridentifikasi}

Gejala yang ditemukan pada daun adalah tepi dan ujung daun terlihat mengering. Dari hasil pengamatan mikroskopis yang dilakukan, miselium memilliki ukuran lebih dari $100 \mu \mathrm{m}$. Konidianya berbentuk bulat dan memiliki ukuran diameter $1-2 \mu \mathrm{m}$. Konidia bergabung dalam suatu tempat. Ujung hifa berbentuk agak bulat. Konidia yang bergabung tidak melekat pada hifa. Jamur ini masuk ke dalam kelas Deuteromycetes.

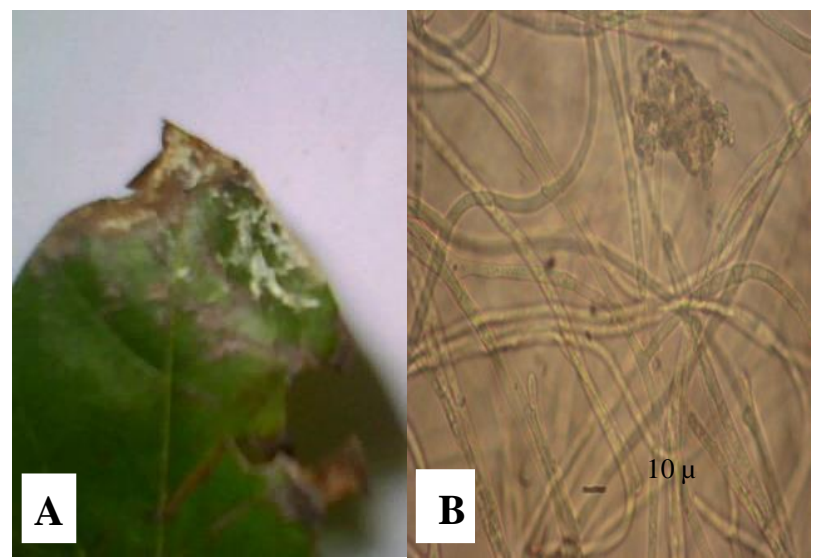

Gambar 16. (A) Gejala yang ditemukan pada daun; (B) Penampakan mikroskopis miselia dan konidia jamur yang ditemukan pada daun

\section{Jamur pada daun yang belum teridentifikasi}

Gejala yang ditimbulkan oleh jamur ini adalah mengeringnya bagian daun. Dari hasil penampakan mikroskopis, hifa memiliki ukuran lebih dari $70 \mu \mathrm{m}$. Hifa memiliki cabang dan bersekat, pada miselium terdapat tonjolan kecil. Konidia tersebar secara soliter dan gabungan. Konidia yang bergabung melekat pada hifa. Konidia memiliki ukuran diameter $1-2 \mu \mathrm{m}$.

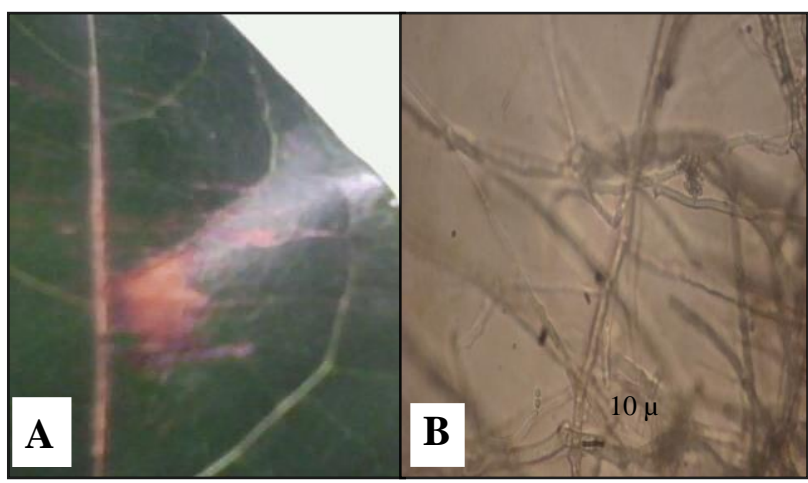

Gambar 17. (A) Gejala yang ditemukan pada daun; (B) Penampakan mikroskopis miselia dan konidia jamur yang ditemukan pada daun

\section{KESIMPULAN}

Hasil penelitian diperoleh sepuluh jenis jamur yang menyerang tanaman mahoni. Tujuh jenis jamur telah teridentifikasi sedangkan tiga jenis lainnya belum dapat teridentifikasi. Jamur tersebut menyerang bagian akar, batang, daun dan buah tanaman mahoni. Jamur-jamur tersebut adalah Rhizopus arrhizus Fischer; Mucor racemosus Fres; Mycogone rosea Link; Absidia corymbifera (Cohn.) Sacc \&Trotter; Monilia sitophila (Mont.) Sacc; Cladosporium spharospermum Penzig; dan Myrothecium verrucaria (Orig.). Jamur yang menyerang pada bagian akar adalah Absidia corymbifera (Cohn.) Sacc dan Cladosporium sphaerospermum Penzig. Mycogone rosea Link dan Monilia sitophila (Mont.) Sacc menyerang daun. Jamur Rhizopus arrhizus Fischer dan Myrothecium verrucaria (Orig.) menyerang bagian batang tanaman sedangkan Mucor racemosus Fres. menyerang buah mahoni.Setiap jamur hanya menyerang satu bagian saja pada tanaman mahoni, hal ini dapat terjadi karena jamur hanya akan bersifat patogen pada inang yang sesuai, sedangkan pada inang yang tidak sesuai, jamur tersebut hanya bersifat saprofit atau menumpang saja tanpa merusak bagian tersebut. 


\section{E. DAFTAR PUSTAKA}

Alexopoulus, C.J., Mims, dan Blackwell. 1996. Introductory Mycology. Edisi keempat. John Wiley dan Sons, Inc., (edisi keempat). New York. Amerika Serikat.

Barnett, H. L. dan B.B. Hunter. 1980.lllustrated Genera of Imperfect Fungi.The American Phytopathological Society. St. Paul, Minnesota. Amerika serikat.

Fassatiova, O. 1986. Moulds and Filamentous Fungi in Technical Microbiology. (Progress in Industrial Microbiology ; V. 22). Elsevier Science Publishing Company; Inc. Cshechoslavakia.

Kirk, P. M. 2008. ISF Index Fungorum: M. verrucaria. Index Fungorum Web site: http://www.indexfungorum.org/Names/ NamesRecord.asp?Record ID = 319837 [12 Mei 2017]
Praweda. 2008. Ciri-ciri dan Klasifikasi Jamur. http://bebas.vlsm.org/v12/sponsor/Sponsor-Pendamping/ Praweda/Biologi/0025\%20Bio\%201-5b.htm [19 Mei 2017].

Rogers. 2001. The Mushrooms: Monilia sitophilla. Roger Plants Web site: http://www.rogersmushrooms.com/gallery/DisplayBlock bid 6764.asp [19 Mei 2017] .

Rahayu, S. 1998. Penyakit Tanaman Hutan di Indonesia. Kanisisus. Deresan, Yogyakarta.

Streets, R.B. 1980. Diagnosis Penyakit Tanaman. Alih Bahasa: Imam Santoso. P.T. Gede Jaya. Bogor.

Tambunan, B. dan D. Nandika. 1982. Deteriorasi Kayu oleh Faktor Biologis. Departemen Hasil Hutan, Fakultas Kehutanan, Institut Pertanian Bogor. Bogor. 